\title{
Marsh Fritillary (Euphydryas aurinia) in the Czech Republic: monitoring, metapopulation structure, and conservation of an endangered butterfly
}

\author{
Vladimir Hula, Martin Konvicka, Alois Pavlicko and Zdenek Fric*
}

Hula, V., Konvicka, M., Pavlicko, A. \& Zdenek, F. 2004: Marsh Fritillary (Euphydryas aurinia) in the Czech Republic: monitoring, metapopulation structure, and conservation of an endangered butterfly. - Entomol. Fennica 15: 231-241.

Thirty colonies of the Marsh Fritillary (Euphydryas aurinia) have recently been recorded in Western Bohemia, Czech Republic. The majority of colonies are small, their total area are $1.5 \mathrm{~km}^{2}$. Small size and intensive grazing/mowing were positively associated with observed declines/extinctions, while abandonment threatens the colonies in the longer term. Short distances to nearest colonies buffered against declines. High colony turnover, asynchronous local dynamics pointed and the species' biotope requirements all point to a dynamic metapopulation structure; patterns of connectivity revealed that there are several metapopulations within the region. Because conserving the species within its extant sites seems unsustainable in the long term, restoration of its habitats is proposed.

V. Hula, Department of Zoology, School of Agriculture, Mendel University, Zemedelska 1, CZ-61301 Brno, Czech Republic

M. Konvicka, Department of Ecology and Conservation Biology, Institute of Entomology, Czech Academy of Sciences, Branisovska 31, CZ-37005 Ceske Budejovice, Czech Republic; E-mail: konva@bf.jcu.cz

A. Pavlicko, National Park Sumava, 1. Maje 260, CZ-385 01 Vimperk, Czech Republic.e-mail: alois.pavlicko@npsumava.cz

Z. Fric (correspondent author), Department of Zoology, School of Biological Sciences, University of South Bohemia, Branisovska 31, 37005 CZ-370 05 Ceske Budejovice, Czech Republic; \& Department of Ecology and Conservation Biology, Institute of Entomology, Czech Academy of Sciences, Branisovska 31, CZ37005 Ceske Budejovice, Czech Republic; E-mail zdenek.fric@tix.bf.jcu.cz

Received 27 February 2004, accepted 27 August 2004

\section{Introduction}

The Marsh Fritillary Euphydryas aurinia (Rottemburg, 1775) (Nymphalidae: Melitaeinae) ranks among the most threatened butterflies in Europe. This inhabitant of unimproved marshy meadows has declined continentally due to land drainage, agricultural intensification, and aban- donment of marginal lands (Van Swaay \& Warren 1999). It is included in Annex II of the EEC/EU Habitat Directive, and legally protected in many European countries. The butterfly is highly selective for both quality and spatial distribution of habitats (Porter 1984, Munguira et al. 1997, Lewis \& Hurford 1997). It persists in landscapes via metapopulation dynamics, forming spatially re- 


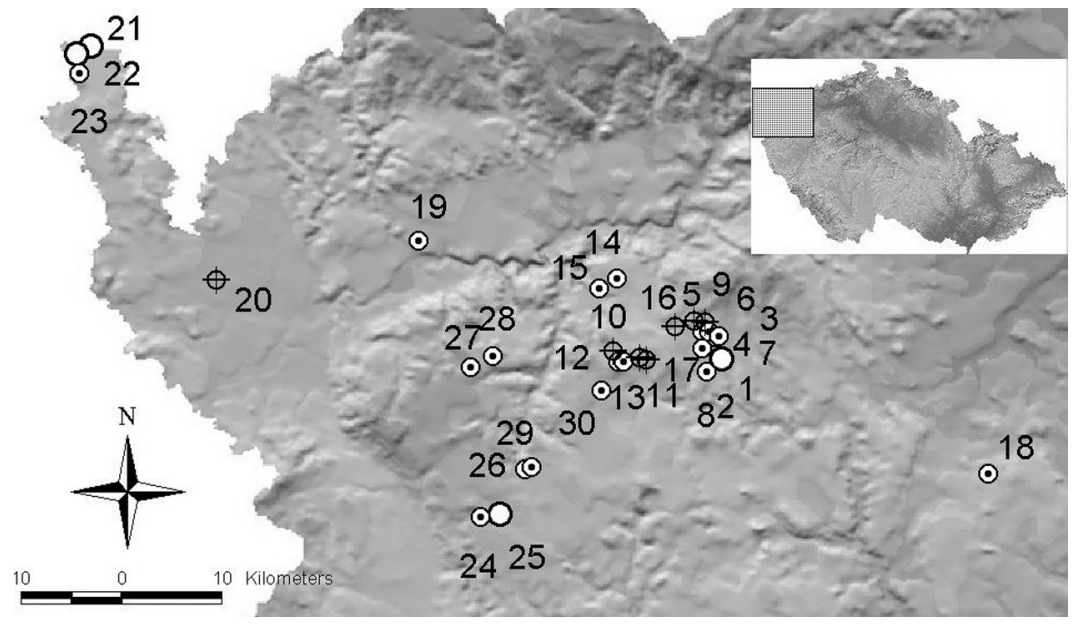

Fig. 1. Western Bohemia, with positions of extant (and recently extinct) colonies of Euphydryas aurinia. The symbols distinguish large colonies (>50 larval nests; empty circles), small to intermediate colonies (circles with dark centres), and colonies that had gone extinct in 2001-2003 (crossed circles). stricted colonies interconnected by adult dispersal (Warren et al. 1994, Wahlberg et al. 2002a). The practices maintaining its habitats differ regionally: British populations inhabit pastures (Asher et al. 2001), hay meadows are colonised in Central Europe (Anthes et al. 2003a, b, Konvicka et al. 2003), and woodland clearings are inhabited in Scandinavia (Wahlberg et al. 2002b). In addition, the species varies geographically in host plant use (e.g., Singer et al. 2002, Wahlberg et al. 2001, Wang et al. 2004), life history (Eliasson \& Shaw 2003) and genetic structure of populations (Descimon et al. 2001).

Until recently, little has been known about the ecology of E. aurinia in Central Europe. In the Czech Republic, a detailed survey of the species' distribution has been carried out since 2000. It has revealed that the butterfly retreated from over $60 \%$ of its 20 th century range and became restricted to the region of Western Bohemia (Hula et al. 2002; see also Fig. 1). A study of larval habitat selection revealed a preference for large and clumped host plants growing at dry, nitrogenpoor and short-sward patches within humid meadows (Konvicka et al. 2003), and similar patterns apply to prealpine Bavaria (Anthes et al. 2003a, b).

Here, we focus on landscape-level patterns in distribution of Euphydryas aurinia in the Czech Republic. We describe the spatial distribution of colonies; estimate their size, report on management and currently faced threats; and analyse changes in colony sizes observed during a period of three years. We document that the species ex- hibits a metapopulation structure, argue that clusters of adjoining colonies should be conserved as individual units, and that landscape-level restoration of habitats is necessary to safeguard the butterfly in the long-term.

\section{Material and methods}

\subsection{The butterfly}

Adult flight of E. aurinia lasts from the end of May until late June in Western Bohemia. Females lay clusters of eggs on leaves of their sole regionally used host plant, Succisa pratensis (Moench, 1794). Larvae hatch in July and feed communally in silken webs. They reach fourth instar in September and weave more compact hibernation webs hidden near ground within $S$. pratensis rosettes. They resume feeding shortly after snowmelt and feed first in loose groups and then solitarily on fresh $S$. pratensis leaves until pupation.

\subsection{Survey of colonies}

Prior to 2000, only four colonies (numbers 7, 18, 19,20 in Fig. 1) of E. aurinia were known to local lepidopterists (Konvicka et al. 2003). We searched for additional colonies by visiting historical sites and checking other humid grasslands throughout the area of distribution of the butterfly, using recollections of local naturalists, topo- 
Table 1. Overview of data collected during monitoring of larval webs, and mark-recapture of adults, of Euphydryas aurinia in the Czech Republic, 2001-2003. Numbers of sites correspond with the numbers in Fig. 1. Larval abundances are expressed on a semiquantitative scale: 0 ; 1 web; $2:<5$ webs; 3 : $<10 ; 4:<20 ; 5:<30 ; 6$ : $<50$; and 7: $<100$. ex = extinct, i.e. the site was visited, but no larval webs were found, n.a. = data not available.

\begin{tabular}{|c|c|c|c|c|c|c|c|c|c|}
\hline \multirow[b]{2}{*}{ Site } & \multirow{2}{*}{$\frac{2001}{\text { larvae }}$} & \multicolumn{4}{|l|}{2002} & \multicolumn{4}{|l|}{2003} \\
\hline & & larvae & days & marked & recaptures & larvae & days & marked & recaptures \\
\hline 1 & 4 & 4 & 25 & 559 & 400 & 7 & 5 & 298 & 156 \\
\hline 2 & n.a. & 4 & n.a. & - & - & 5 & 4 & 49 & 20 \\
\hline 3 & 3 & 3 & 23 & 229 & 105 & 3 & 20 & 254 & 228 \\
\hline 4 & n.a. & 4 & 23 & 228 & 202 & 4 & 21 & 369 & 497 \\
\hline 5 & 4 & 3 & 23 & 96 & 127 & ex & 20 & 136 & 189 \\
\hline 6 & n.a. & 3 & 23 & 86 & 40 & 3 & 20 & 138 & 178 \\
\hline 7 & 4 & 3 & 23 & 96 & 137 & 2 & 20 & 65 & 93 \\
\hline 8 & n.a. & n.a. & n.a. & - & - & 4 & 1 & 7 & 1 \\
\hline 9 & 2 & ex & 1 & 1 & 0 & ex & n.a. & - & - \\
\hline 10 & 4 & ex & 1 & 7 & 3 & ex & 1 & 4 & 1 \\
\hline 11 & n.a. & 3 & 3 & 57 & 14 & 3 & 1 & 102 & 29 \\
\hline 12 & 3 & ex & 3 & 0 & 0 & ex & 1 & 0 & 0 \\
\hline 13 & 2 & 1 & 2 & 5 & 2 & 1 & 1 & 1 & 1 \\
\hline 14 & 5 & 4 & 1 & 43 & 13 & 5 & 3 & 103 & 22 \\
\hline 15 & 3 & 2 & n.a & - & - & 2 & 3 & 15 & 16 \\
\hline 16 & 1 & ex & n.a & - & - & ex & n.a. & - & - \\
\hline 17 & 4 & 3 & 2 & 40 & 10 & ex & 1 & 0 & 0 \\
\hline 18 & 4 & 1 & n.a. & - & - & 2 & n.a. & - & - \\
\hline 19 & 4 & 2 & n.a. & - & - & 2 & n.a. & - & - \\
\hline 20 & 3 & ex & n.a. & - & - & ex & n.a. & - & - \\
\hline 21 & n.a. & 7 & n.a. & - & - & 7 & n.a. & - & - \\
\hline 22 & n.a. & 7 & n.a. & - & - & 7 & n.a. & - & - \\
\hline 23 & n.a. & n.a. & n.a. & - & - & 4 & n.a. & - & - \\
\hline 24 & n.a. & 6 & n.a. & - & - & 6 & n.a. & - & - \\
\hline 25 & n.a. & 7 & n.a. & - & - & 7 & 1 & 101 & 7 \\
\hline 26 & n.a. & 4 & n.a. & - & - & 4 & 1 & 46 & 10 \\
\hline 27 & n.a. & 2 & n.a. & - & - & 2 & 1 & 4 & 1 \\
\hline 28 & n.a. & n.a. & n.a. & - & - & 2 & 1 & 6 & 2 \\
\hline 29 & n.a. & 2 & n.a. & - & - & 2 & 1 & 8 & 8 \\
\hline 30 & 3 & 3 & 1 & 23 & 5 & 4 & n.a. & - & - \\
\hline
\end{tabular}

graphic maps, aerial photographs, and information of host plant occurrence from vegetation surveys. We thus visited some 100 sites and discovered 26 hitherto unknown colonies. The surveys took place mainly during late August/early September, when the larval webs are most conspicuous, but some sites were discovered during adult period as well.

\subsection{Population size estimates}

During autumn visits, we zigzagged each site and recorded the abundance of larval webs on the fol- lowing ordinal scale: $0 ; 1 ; 2:<5$ webs; $3:<10$; $4:<20 ; 5:<30 ; 6:<50 ;$ and $7:<100$.

To compare larval counts with adult numbers, we needed a method for estimating adult abundance across many sites. Thomas (1983) proposed performing quick estimates across multiple colonies, fitting them to estimates from a wellstudied reference colony, and correcting the result for phenological effects of butterfly emergence. We selected one area with a high density of local colonies (hereafter "main area") for detailed mark-release-recapture (MRR) survey. There were five colonies within $2 \mathrm{~km}^{2}$ (Fig. 1: 3, 4, 5, 6, 7 ), and an additional three colonies $3 \mathrm{~km}$ apart 


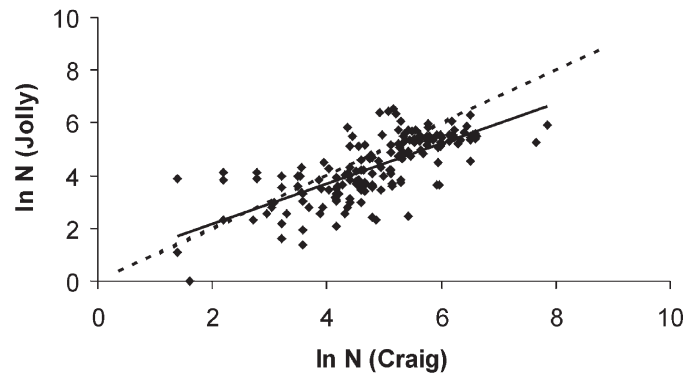

Fig. 2. Regression of Craig's vs. Jolly's daily population size estimates obtained from main area sites. Regression based on 2002 and 2003 results; full line = fitted model, broken line: $y=x$.

(Fig. 1: 1, 2, 8). The MRR was carried out in 2002 (all colonies) and 2003 (the five colonies within $2 \mathrm{~km}^{2}$ ). Marking proceeded on an every day basis, weather permitting, during the entire adult flight. We spent approximately equal time within each colony, marked all netted butterflies with unique numbers, recorded their sex, position of capture and wing wear (scale 1-4), and released them at capture points. In addition, we visited as many as possible of the more distant ("peripheral") colonies, and spent there two to four person-hours per visit. Table 1 summarises the marking effort.

We calculated two estimates of adult numbers for the main area sites. The first was the JollySeber-Cormack [JSC] method (e.g. Jolly 1965), which gives one-day estimates for intensively sampled populations with births, deaths and interchange of individuals (Williams et al. 2001), using model A in the program Jolly (Pollock et al. 1990).

The second was the single-marking method of Craig (1953), which estimates population size from numbers of animals and numbers of capture events, assuming Poisson's distribution of individuals captured zero times, once, two times, etc. (Pollard 1977). We used only the latter method for peripheral colonies.

The Craig method frequently overestimates true population sizes (Gall 1984). To correct for the bias, we regressed, separately for each study year, the (ln-transformed) daily estimates from main area sites obtained by the two methods (Fig. 2 ). We then used the regressions to convert the Craig estimates from peripheral sites into respective JSC estimates.

It remained to convert the JSC estimates from peripheral sites to a mutually comparable phenological date. We used colony 4 from the main area (the densest data available) as a template, and converted the JSC estimates from peripheral sites into the JSC estimate expectable at peak flight (Fig. 3).

To estimate adult numbers for the colonies where no marking was done, we regressed, separately for each year, the (ln-transformed) peakflight JSC estimates against larval web counts for the colonies from which both estimates were available, and used the regressions to predict peak adult numbers for remaining colonies.

\subsection{Parameters of sites}

Individual colonies were characterised by (1) Area, defined as distinct biotope borders such as margins of forest or improved meadow; (2) Host plant abundance (ordinal scale, $1:<10,2:<50$, 3: $<100,4:<500,5:<1,000$, and $6:$ above 1,000 rosettes); (3) Management (None, Intensive pasture, Random [= light, or erratic] pasture, Mowing once a year, Mowing twice a year, and Trampling by game animals), recorded as a percentage of patch area (rounded to tens of per cent); and (4) Current threats, i.e., overgrazing, intensive haymaking, successional overgrown, afforestation, nutrient spillovers from adjoining fields, and land drainage, again in percentages of patch area affected.

To express the connectivity of sites, we used two measures. The neighbourhood distance ["Neighbourhood"] was simple centre-to-centre distance to the nearest colony. The landscape connectivity ["Connectivity"] took into account the distances of a given site to all other sites, weighting the distances by site areas. Following Moilanen \& Nieminen (2002),

$S_{j}=\sum e^{\left(-\alpha \cdot d_{j k}\right)} A_{k}^{\zeta_{i m}}$

where $\mathrm{A}_{k}$ are areas of surrounding sites and $\mathrm{d}_{j k}$ are centre-to-centre Euclidean distances from site $j$ to $k$. The parameters $\alpha$ and $\zeta_{\text {im }}$ scale the effect of distance on migration and the effect of patch area on immigration, respectively. We estimated them from MRR data on dispersal, 2002, sexes combined, using the Virtual Migration model by 
2
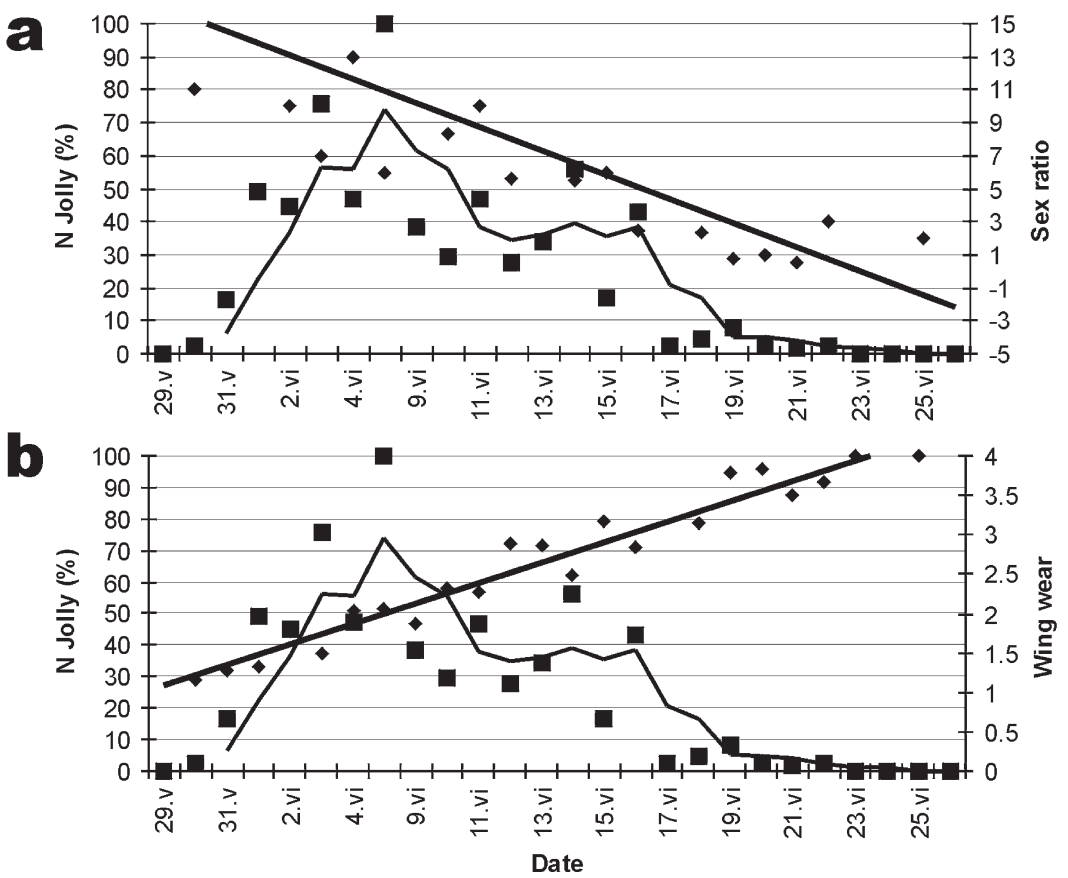

Fig. 3. Method used for recalculation of estimates of adult numbers from peripheral colonies to maximum potential adult numbers, year 2002, males. - a. Capture sex ratio fitted against days (straight line) indicate daily phenological states of the population. $-b$. Wing wear fitted against days (straight line) indicate daily phenological states of the population. In (a) and (b), black squares = Jolly's one-day estimates from the well-studied colony 4 that were fitted using 3rd period moving mean; by setting maximum daily estimates as $100 \%$, the resulting line gives a proportion of the maximum population size present in particular days. The recalculation of estimates (for a and b) from peripheral colonies proceeds as follows: (i) Craig's estimates are transferred to JSC estimates, using Equation 5, above; (ii) capture sex ratio and wing wear recorded from a peripheral colony give proportions of maximum population size present there at marking; (iii) if the two proportions differ, their middle value is used; (iv) the estimated population size is then transferred to maximum population size, i.e. $100 \%$.

Hanski et al. (2000). The values were $\alpha=1.5$ and $\zeta_{\mathrm{im}}=0.11$. Details of the Virtual Migration approach will be presented elsewhere.

\subsection{Predictors of decrease and extinctions}

We constructed multiple regression models of decrease/extinction against site parameters, using generalised linear models with binary dependent variables (decrease vs. stability and/or increase, and extinction vs. persistence) and logit-link function. For "decreasing", we considered the colonies where the abundance of larval nests dropped by 2 points at the ordinal scale used for nests counts (see section 2.3.) during the three years. Percentual predictors (i.e., those referring to management) were arcsine transformed prior the analyses. Following single-term regressions for all predictors, we used stepwise forward selection to select the best-fitting model, comparing model fits against respective null models using the Akaike information criterion (AIC) and $F$ tests. We used S-plus 2000 (S-plus 1999) for the computations.

\section{Results}

Fig. 1 shows the locations of 30 extant (and re- 
cently extinct) colonies of $E$. aurinia in Western Bohemia. The majority of the colonies belong to distinct clusters, but some colonies are separated from the nearest colony by $>10 \mathrm{~km}$ of unoccupied areas.

\subsection{Estimates of population size}

We marked 1595 adults in 2002 and 1793 in 2003, and obtained 1097 and 1558 recaptures (Table 1). For the main area (sites 1, 3, 4, 5, 6 and 7 in 2002 and 3, 4, 5, 6 and 7 in 2003), regressing of the daily Craig and Jolly estimates gave the relationships:

$\ln N_{\text {JSC }}=0.72( \pm 0.067$ S. E. $) * \ln \left(N_{\text {Craig }}\right)$

$+0.96( \pm 0.340$ S. E.) (year 2002)

and

$\ln N_{\text {JSC }}=0.86( \pm 0.104$ S. E. $) * \ln \left(N_{\text {Craig }}\right)$

-0.03 ( \pm 0.498 S. E.) (year 2003)

Both regressions were significant $\left(2002: F_{1,120}=\right.$ 113.3, $p<0.001, R^{2}=0.49 ; 2003: F_{1,43}=68.0$, $\left.p<0.001, R^{2}=0.61\right)$ and neither their slopes nor their intercepts differed (slope: $t_{74}=-1.75$, twotailed $p=0.08$; intercept: $t_{74}=-1.84$, two-tailed $p=0.07)$. We hence constructed the common regression,

$\ln N_{\text {JSC }}=0.76( \pm 0.057$ S. E. $) * \ln \left(N_{\text {Craig }}\right)$ $+0.64( \pm 0.284$ S. E. $)$

Plotting it against $y=x$ line (Fig. 2) showed that Craig's method underestimated population size for low adult numbers ( $<100$ individuals), and overestimated it for large populations $(>1,000$ individuals).

Fig. 3 illustrates the method used for re-calculating one-day adult estimates to numbers in peak flight. Use of the method was justified, because the male to female ratio decreased with the season (logit regression, 2002: $\chi^{2}=38.3$, d.f. $=1$, $p<0.0001 ; 2003: \chi^{2}=26.4$, d.f. $\left.=1, p<0.0001\right)$ and wing wear gradually increased $\left(2002: F_{120}=\right.$ 344.3, $p<0.001$; 2003: $\left.F_{1,17}=90.3, p<0.001\right)$.

The regressions of the (JSC-estimated) peak adult numbers against larval counts were $\ln \left(N_{\text {JSCmax }}\right)=0.78( \pm 0.29$ S. E. $) *($ nest count $)$

$+2.69( \pm 0.873$ S. E.) (year 2002)

and

$\ln \left(N_{\text {JSCmax }}\right)=0.58( \pm 0.100$ S. E. $) *$ (nest count)

$+2.58( \pm 0.467$ S. E. $)($ year 2003$)$

They were significant (2002: $F_{1,9}=7.2, p<0.05$, $R^{2}=0.44,2003: F_{1,15}=33.4, p<0.001, R^{2}=0.69$ ) but differed in slopes (slopes: $t_{24}=2.39, p<0.05$, intercepts: $\left.t_{24}=1.89, p=0.07\right)$. Hence, we could not use a single relationship for recalculating larval and adult counts.

Using equations 6 and 7, we estimated the total Czech population of E. aurinia. For 2003, i.e. the year with the most complete survey, the estimate was $\approx 5,000$ using the 2003 parameters and $\approx 8,000$ using mid-values between parameters from 2002 and 2003 (slope: 0.65, intercept: 2.62). Although such estimates are crude and total emergence exceeds the numbers in peak flight, they illustrate how small the Czech population of E. aurinia in fact is. Regarding year-to-year variation, the estimates from 11 sites surveyed each year gave annual estimates $\approx 2900(2001), \approx 1700$ (2002) and $\approx 1500$ (2003), with the coefficient of variation 0.28 .

\subsection{Parameters of colonies}

Out of the 30 extant colonies, 23 contained $<10$ larval nests (i.e., ca. 70 adults in 2002 and ca. 150 adults in 2003) whereas four contained $>100$ nests or $>1,000$ adults. Areas of 23 colonies were smaller than five hectares, whereas two colonies exceeded 25 hectares. The summed inhabited area was $1.44 \mathrm{~km}^{2}$.

If management of the colonies is expressed proportionally to their total area, than two thirds of the area is neglected land (neither mown nor grazed, while $30 \%$ of the total area is either grazed or mowed (Fig. 4a). Notably, although trampling of game animals affect only small proportions the sites, the host plants of E. aurinia tend to concentrate at these disturbed patches (cf. Konvicka et al. 2003).

Twelve of the colonies ( $40 \%$ of total) are threatened by succession or by afforestation. On 


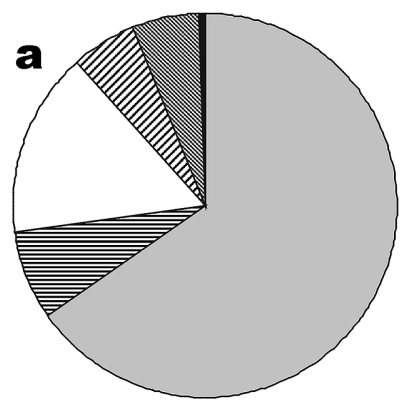

$\square$ no management 目 mowing $\square$ intensive farming $\nabla$ erratic grazing trampling घhrub cutting

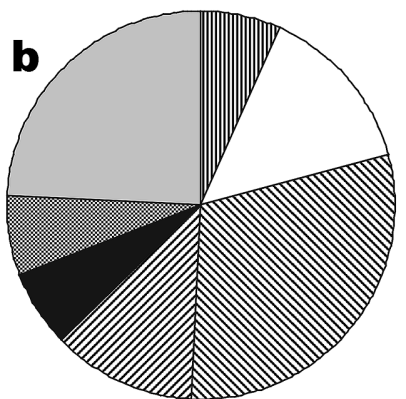

\section{III overgrazing} $\square$ intensive mowing \$succession afforestation autrophisation drainage $\square$ no threat

Fig. 4. Overview of recent (2003) management, and threats, of the 30 sites inhabited in 2000-2003 by Euphydryas aurinia in Western Bohemia, including sites where the butterfly had gone extinct during the period. - a. Management, recalculated to percentage cover of individual sites. $-b$. Threats, related to the percentage of thus affected individual sites.

the contrary, ten sites are threatened by overmanagement: they are mown or grazed too intensively, affected by past drainage, or by leakage of nutrients from adjoining farms (Fig. 4b). Related to total inhabited area, the picture is slightly more optimistic, as one-third of the total is not threatened recently, while one-third is threatened by succession/afforestation and one-third by too-intensive farming.

\subsection{Evidence for metapopulation dynamics}

Two prerequisites of metapopulation dynamics are asynchronous within-site dynamics and limited, but existing, dispersal (Hanski 1999). Regarding the former, three out of 24 colonies surveyed for $>1$ year increased in numbers, twelve decreased and seven went extinct (Fig. 1). Regarding dispersal, it suffices to state that out of 600 butterflies recaptured at least once in 2002, 378 did not leave their sites of original capture.
The mean movement was $151(\mathrm{SD}=537.8)$ meters, 22 butterflies crossed distances $>1 \mathrm{~km}$ (males: 18, females: 4), and one female was captured after dispersing from site 14 to $11(8.5 \mathrm{~km})$. Hence, some individuals were capable of considerable inter-colony movements.

\subsection{Correlates of decrease and extinction}

Decreases in colony size (Table 2) were less likely at large sites that contained high numbers of rosettes of $S$. pratensis and were mown once a year, and more likely at intensively grazed sites. They were more likely the longer the distance to the nearest colony, but did not depend on landscape connectivity $\left(\mathrm{S}_{j}\right)$. The multiple-regression model accounted for $51.7 \%$ of the variation and contained hostplant abundance (positively correlated with area, Spearman's $r=0.71, p<0.001)$ and the distance to the nearest colony.

Extinctions (Table 3) were less likely in colonies with high abundance of host plants that were mown once a year. Positive predictors of extinction included grazing (both intensive and erratic) and intensive (twice-a-year) mowing. Host plant abundance, which was the only predictor of the final model, explained $47.2 \%$ of the variation.

\section{Discussion}

Although increased survey intensity considerably increased the number of known sites of $E$. aurinia in the Czech Republic, most of the colonies are small, the entire flight area does not exceed $1.5 \mathrm{~km}^{2}$, and the butterfly remains seriously threatened.

\subsection{Monitoring}

Our estimates of the population size from peripheral localities relied on comparisons with intensively sampled sites. The fact that the relationships between estimates obtained by the quick Craig's and relatively laborious JSC methods were consistent across two successive years may greatly aid to future monitoring. Naturally, our approach relied on several simplifying assump- 
Table 2. Factors associated with decreases of colony size (expressed as a decline of larval web abundance by $>2$ ordinal points used for larval surveys). GLM regressions with binarily coded dependent variable (decrease vs. stability of increase). "Direction" indicates positive or negative relationship, F-tests refer to comparisons with null model. Only colonies followed for at least two years were analysed. ${ }^{*} p<0.05 ;{ }^{* *} p<0.01 ;{ }^{* *} p<0.001$.

\begin{tabular}{|c|c|c|c|c|c|c|c|}
\hline & Direction & $\begin{array}{l}\text { Resid. } \\
\text { deviance }\end{array}$ & $d f$ & Deviance & $C p$ & $F$ & $p$ \\
\hline Null model & & 35.6 & 26 & & 37.4 & & \\
\hline \multicolumn{8}{|l|}{ Single-term models } \\
\hline Area & - & 28.6 & 1,24 & 7.0 & 34.1 & 3.8 & * \\
\hline Connectivity & & 33.5 & 1,24 & 2.1 & 40.0 & 0.4 & n.s. \\
\hline Neighbourhood & + & 30.4 & 1,24 & 5.2 & 34.5 & 5.1 & * \\
\hline No management & & 35.6 & 1,24 & 0.0 & 39.9 & 0.0 & n.s. \\
\hline Mowing once & - & 27.7 & 1,24 & 7.9 & 30.9 & 9.8 & ** \\
\hline Mowing twice & & 35.5 & 1,24 & 0.1 & 39.8 & 0.1 & n.s. \\
\hline Intensive pasture & + & 31.3 & 1,24 & 4.3 & 35.3 & 4.3 & * \\
\hline Random pasture & & 32.8 & 1,24 & 2.8 & 37.0 & 2.8 & n.s. \\
\hline Trampling & & 34.7 & 1,24 & 0.9 & 39.1 & 0.8 & n.s. \\
\hline $\begin{array}{l}\text { Host plant abundance } \\
\text { Best model }\end{array}$ & - & 20.9 & 1,24 & 14.7 & 24.2 & 17.7 & $* * *$ \\
\hline Hostplant + neighbourhood & & 17.2 & 2,23 & 18.4 & 22.1 & 11.3 & $* * *$ \\
\hline
\end{tabular}

Table 3. Factors predicting extinctions of colonies. GLM regressions with binarily coded dependent variable (extinct $v s$. not extinct). F-tests refer to comparisons with null model, only colonies followed for at least two years were used in the analysis. "Hostplant" was the only variable that entered the final model. ${ }^{*} p<0.05 ;{ }^{* *} p<0.01$; ${ }^{* * *} p<0.001$.

\begin{tabular}{llllllll}
\hline & $\begin{array}{c}\text { Direction } \\
\end{array}$ & $\begin{array}{l}\text { Resid. } \\
\text { deviance }\end{array}$ & $d f$ & Deviance & $C p$ & $F$ & $p$ \\
\hline $\begin{array}{l}\text { Null model } \\
\text { Single-term models }\end{array}$ & & 30.9 & 26 & & 32.8 & & \\
Area & - & 25.8 & 2,24 & 5.1 & 31.4 & 2.7 & + \\
Connectivity & & 27.7 & 2,24 & 3.2 & 34.1 & 1.5 & n.s. \\
Neighbourhood & & 30.9 & 1,25 & 0.1 & 35.2 & 0.1 & n.s. \\
No management & - & 29.2 & 1,25 & 1.8 & 33.6 & 1.6 & n.s. \\
Mowing once & 25.9 & 1,25 & 5.0 & 29.1 & 6.3 & $*$ \\
Mowing twice & + & 30.8 & 1,25 & 0.1 & 35.2 & 0.1 & n.s. \\
Intensive pasture & 25.0 & 1,25 & 5.9 & 29.0 & 5.9 & $*$ \\
Random pasture & + & 26.0 & 1,25 & 4.9 & 30.2 & 4.7 & $*$ \\
Trampling & & 30.6 & 1,25 & 0.3 & 34.9 & 0.3 & n.s. \\
Hostplant abundance & - & 16.3 & 1,25 & 14.6 & 20.7 & 13.4 & $* *$ \\
\hline
\end{tabular}

tions, including reliability of the JSC method, monotonous increase of wing wear and monotonous decrease of sex ratio (i.e., protandry) during season. However, the JSC method can always be substituted by more sophisticated abundance estimates (cf. Schtickzelle et al. 2003), and both protandry and increasing wing wear are commonplace in butterflies with discrete generations (e.g., Fagerstrom \& Wiklund 1982).

The regressions of adult numbers against larval counts differed between the years. This might be due to low sample size in 2002, when larval and adult counts were available for just eleven colonies. In addition, changing management of the sites could distort any relationships between adult and larval numbers. We observed this at site 
5, in 2003, where females were quite abundant (captures: 61, $N J S C_{\max }=92$ ) but all nests were destroyed by mowing in August. Hence, caution is required for using larval abundances to predict adult numbers, and vice versa. Regardless, the counts of larval webs sufficed to detect relative population changes, and thus remain efficient for cheap and quick monitoring.

\subsection{Metapopulation structure}

The asynchronous dynamics of local colonies and limited dispersal pointed to a metapopulation structure similar to that found in Bavaria (Anthes et al. 2003a, b) and other regions (Warren 1994, Wahlberg et al. 2002b, Wang et al. 2003, 2004). This similarity among distant regions supports the notion that metapopulation dynamics is an intrinsic trait of this species (Wahlberg 2000). In agreement with metapopulation theory, small area and isolation of patches adversely affected colony survival. However, we did not find any effect of overall landscape connectivity. This indicates that dynamics of individual colonies were influenced by the situation in their close vicinity rather than by the situation in the entire area, and that there are several mutually independent metapopulation systems. Since the proximity to other colonies buffered against decline and extinction, these systems should be managed as individual conservation units. Joyce \& Pullin (2003) observed a similar situation in Britain, where no genetic differentiation existed within clusters of E. aurinia colonies, but isolation by distance was evident among the clusters.

The area surveyed in this study was relatively sparsely occupied compared to, e.g., the metapopulation of Melitaea cinxia on the Aland Islands, Finland (Hanski 1999). Although there still is a possibility that we failed to discover some colonies, it is unlikely that we missed many of them, or that some of the undetected colonies are large. The entire area suffered massive land drainage and meadow improvement schemes in the 1970s and 1980s, and the remaining humid meadows form tiny, and easily distinguished, islets in an otherwise unsuitable landscape.

Contrary to most metapopulation studies, we did not consider the existence of empty patches.
Dennis et al. (2003) argued that while it is easy to spot a patch if the organism is present, without it one can never be certain whether a site contains all necessary resources. For E. aurinia, the simple presence of the host plant does not suffice to define habitat, as its larvae prefer a specific vegetation structure (Konvicka et al. 2003) and adults require rich nectar supply and sheltered spots utilised for perching (unpublished observations). Separation of mating and egg-laying patches was reported for at least one checkerspot species (Schwarzwalder et al. 1997). The uncertainty regarding empty patches explains why we did not observe any (re)colonisation. To observe it, we should have observed extinction first, and observing both events at one spot was very unlikely during our short-term study.

\subsection{Site management and conservation guidelines}

Anthes et al. (2003a, b) argued that joint effects of quality and spatial distribution of habitats affects the persistence of E. aurinia in Bavaria. Our observation that intensive grazing and mowing had deleterious effects on colony persistence corroborates this claim. Intensive grazing reduces nectar availability (Dolek \& Geyer 1997, Anthes et al. 2003a) and host plant size (Konvicka et al. 2003), whereas late-season mowing destroys larval webs. Less expectable were the deleterious effects of light grazing (Table 3 ). We observed the effect at two fenced streamsides adjoining improved pastures (sites 10 and 17), where only a few days of cattle presence sufficed to destroy host plants with egg batches. However, both colonies were very small prior to this event.

On the other hand, prolonged abandonment leads to encroachment of sites by tall vegetation, shrubs and trees. These contradicting effects point to the paradox that conditions beneficial for the butterfly develop shortly after cessation of mowing or grazing, but persist for a relatively short time. In the past, traditional farming had maintained fine-grained landscape mosaics of varying managements, which allowed the butterfly to persist by tracking transitorily neglected patches (cf. Wahlberg et al. 2002b). However, such landscape mosaics no longer exist. Al- 
though we might try to mimic them within individual colonies (Konvicka et al. 2003), the high colony turnover indicates that restricting conservation efforts to individual colonies would be unsustainable in the long term.

Extending the recently inhabited area offers the only long-term choice. The methods available include re-establishment of mowing at abandoned sites, and diminishing grazing/mowing intensity at improved meadows and pastures (Barnett \& Warren 1995). At present, both the space and resources for a landscape-scale restoration are available. The butterfly inhabits regions unsuitable for intensive agriculture, where farming already depends on government subsidies. The total sums spent annually are difficult to ascertain, but it is illustrative that the single farmer who manages our main area receives annual subsidies for 300 hectares, i.e., for more land than is inhabited by the species at present. Therefore, managing the area for the butterfly should not incur any additional cost to taxpayers.

A species action plan for E. aurinia, now under preparation in the Czech Republic, advocates the following modifications of the conditions qualifying local farmers for subsidies: execution of hay harvests in a patchy manner with portions of meadows left uncut each year, lower stocking of pastures, and not fertilising meadows. It also proposes cessation of governmental support for afforestation, since wooded conditions restrict adult movements (Norberg et al. 2002). The ultimate goal is to enhance the inhabited area fivefold, which seems realistic given the extent of subsidised (or abandoned) grasslands.

Acknowledgements. We dedicate this paper to the memory of the late J. Franz, local lepidopterist from Rybnicna, near Bochov, who for years followed the fate of the few thenknown colonies of E. aurinia. For help in the field, we thank L. Cizek, A. Faltynkova, J. Hrcek, P. Kail, B.G. Lai, M. Maradova, J. Piszkiewicz, J. Puza, and T. Schmitt. K. Chobot and P. Marhoul provided us detailed topographic maps, and V. Melichar communicated to us results of vegetation surveys. M. Sweney corrected our English. Comments of two anonymous reviewers considerably improved this paper. Funding was provided by the Czech Ministry of Environment (436/2003 to Sagittaria foundation), the Grant Agency of the Czech Republic (206/03/H034) and the Grant Agency of the Czech Academy of Sciences (B6007306).

\section{References}

Anthes, N., Fartmann, T. \& Hermann, G. 2003a: Wie lässt sich der Rückgang des Goldenen Scheckenfalters (Euphydryas aurinia) in Mitteleuropa stoppen? Naturschutz und Landschaftsplanung 35: 279-287.

Anthes, N., Fartmann, T. \& Hermann, G. 2003b: Combining larval habitat quality and metapopulation structure - the key for successful management of pre-alpine Euphydryas aurinia colonies. - Journal of Insect Conservation 7: 175-185.

Asher, J., Warren, M., Fox, R., Harding P. \& Jeffcoate, G. (eds) 2001: The Millennium Atlas of Butterflies in Britain and Ireland. - Oxford University Press, Oxford. $433 \mathrm{pp}$.

Barnett, L. K. \& Warren, M.S. 1995: Marsh Fritillary Eurodryas aurinia. Species Action Plan. - Butterfly Conservation, Wareham, Dorset. Unpublished technical report.

Craig, C. C. 1953: On the utilisation of marked specimens in estimating populations of flying insects. Biometrika 40: 170-176.

Dennis, R. L. H., Shreeve, T. G. \& Van Dyck, H. 2003: Towards a functional resource-based concept for habitat: a butterfly biology viewpoint. — Oikos 102: 417-426.

Descimon, H., Zimmermann, M., Cosson, E., Barascud B. $\&$ Neve, G. 2001: Genetic variation, geographic variation and gene flow in some French butterfly species. — Genet. Sel. Evol. 33 (Suppl. 1): 223-249.

Dolek, M. \& Geyer, A. 1997: Influence of management on butterflies of rare grassland ecosystems in Germany. - Journal of Insect Conservation 1: 125-130.

Eliasson, C. \& Shaw, M. R. 2003: Prolonged life cycles, oviposition sites, foodplants and Cotesia parasitoids of Melitaeini butterflies in Sweden. - Oedippus 21: $1-42$.

Fagerstrom, T. \& Wiklund, C. 1982: Why do males emerge before females - protandry as a mating strategy in male and female butterflies. - Oecologia 52: 164166.

Gall, L. F. 1984: The effects of capturing and marking on subsequent activity in Boloria acrocnema (Lepidoptera, Nymphalidae), with a comparison of different numerical models that estimate population size. - Biological Conservation 28: 139-154.

Hanski, I. 1999: Metapopulation ecology. — Oxford University Press, Oxford. 308 pp.

Hanski, I., Alho, J. \& Moilanen, A. 2000: Estimating the parameters of survival and migration of individuals in metapopulations. - Ecology 81: 239-251.

Hula, V., Konvicka, M. \& Fric, Z. 2002: Hnedasek chrastavcovy (Euphydryas aurinia). — In: Benes, J., Konvicka, M., Dvorak, J., Havelda, Z., Pavlicko, A., Vrabec, V. \& Weidenhoffer, Z. (eds.), Butterflies of the Czech Republic: Distribution and Conservation I., II.: 468-473. Spolecnost pro Ochranu Motylu, Praha, 857 pp.

Jolly, G. M. 1965: Explicit estimates from capture-recapture data with both death and immigration - Stochastic 
model. - Biometrica 52: 225-247.

Joyce, D. A. \& Pullin, A. S. 2003: Conservation implications of the distribution of genetic diversity at different scales: a case study using the marsh fritillary butterfly (Euphydryas aurinia). — Biological Conservation 114: 453-461.

Konvicka, M., Hula, V. \& Fric, Z. 2003: Habitat of pre-hibernating larvae of the endangered butterfly $E$ phydryas aurinia (Lepidoptera: Nymphalidae): What can be learned from vegetation composition and architecture? - European Journal of Entomology 100: 313-322.

Lewis, O. T. \& Hurford, C. 1997: Assessing the status of the marsh fritillary butterfly (Eurodryas aurinia): An example from Glamorgan, UK. - Journal of Insect Conservation 1: 159-166.

Moilanen, A. \& Nieminen, M. 2002: Simple connectivity measures in spatial ecology. -Ecology 83: 11311145 .

Munguira, M. L., Martin, C., García-Barros, E. \& Viejo, L. J. 1997: Use of space and resources in a Mediterranean population of the butterfly Euphydryas aurinia. Acta Oecologia 18: 597-612.

Norberg, U., Enfjall, K., Leimar, O. 2002: Habitat exploration in butterflies - an outdoor cage experiment. Evolutionary Ecology 16: 1-14.

Pollard, E. 1977: A method for assessing changes in abundance of butterflies. - Biological Conservation 12: $115-124$.

Pollock, K. H., Nichols, J. D., Brownie, C., \& Hines, J. E. 1990: Statistical inference for capture-recapture experiments. - Wildlife Monographs 107.

Porter, K. 1984: Sunshine, sex-ratio and behaviour of the Euphydryas aurinia larvae. - In: Vane-Wright, H. T. \& Ackery, P. R. (eds.), The biology of butterflies: Symposium of the Royal entomological society of London: 309-315. Academic press, London.

Schwarzwalder, B., Lortscher, M., Erhardt, A., Zettel, J. 1997: Habitat utilization by the heath fritillary butterfly, Mellicta athalia ssp. celadussa (Rott) (Lepidoptera: Nymphalidae) in montane grasslands of different management. - Biological Conservation 82: $157-165$.

Schtickzelle, N., Baguette, M. \& Le Boulenge, E. 2003: Modelling insect demography from capture-recapture data: comparison between the constrained linear mod- els and the Jolly-Seber analytical method. - Canadian Entomologist 135: 313-323

Singer, M.C., Stefanescu, C. \& Pen, I. 2002: When random sampling does not work: Standard design falsely indicates maladaptive host preferences in a butterfly. Ecology Letters 5: 1-6.

S-Plus 2000, 1999. S-Plus Guide to Statistics vol. 1. Data Analysis Products Division, MathSoft, Seattle,WA.

Thomas, J. A. 1983: A quick method for estimating butterfly numbers during surveys. - Biological Conservation 27: 195-211.

Van Swaay, C. A. M. \& Warren, M. S. 1999: Red Data Book of European Butterflies (Rhopalocera). - Nature and Environment Series No. 99. Council of Europe, Strasbourg. $260 \mathrm{pp}$.

Wahlberg, N. 2000: The Ecology and Evolution of Melitaeine Butterflies. - Academic dissertation. University of Helsinki.

Wahlberg, N., Kullberg, J. \& Hanski, I. 2001: Natural history of some Siberian melitaeine butterfly species (Nymphalidae : Melitaeini) and their parasitoids. Entomologica Fennica 12: 72-77.

Wahlberg, N., Klemetti, T., Selonen, V. \& Hanski, I. 2002a: Metapopulation structure and movements in five species of checkerspot butterflies. - Oecologia 130: 33-43.

Wahlberg, N., Klemetti, T. \& Hanski, I. 2002b: Dynamic populations in a dynamic landscape: the metapopulation of the marsh fritillary butterfly. - Ecography 25: 224-232.

Wang, Y. F., Chen, J. J., Wang, R. J., Lei, G. C. \& Xu, R. M. 2003: Difference in metapopulation structure and dynamics of two species of coexistent melitaeine butterflies. - Chinese Scientific Bulletin 48: 1239-1246.

Wang, R. J., Wang, Y. F., Chen, J. J., Lei, G. C., Xu, R. M. 2004: Contrasting movement patterns in two species of chequerspot butterflies, Euphydryas aurinia and Melitaea phoebe, in the same patch network . - Ecological Entomology 29: 367-374.

Warren, M. S. 1994: The UK status and suspected metapopulation structure of a threatened European butterfly, the Marsh Fritillary Eurodryas aurinia. - Biological Conservation 67: 239-249.

Williams, B. K., Nichols, J. D., \& Conroy, M. J. 2001: Analysis and management of animal populations. Academic Press, London, 817 pp. 